\title{
Article \\ Can VA-ECMO Be Used as an Adequate Treatment in Massive Pulmonary Embolism?
}

\author{
Raphaël Giraud ${ }^{1,2, *,+} \mathbb{D}$, Matthieu Laurencet ${ }^{1,+}$, Benjamin Assouline ${ }^{1,2}$, Amandine De Charrière ${ }^{1,2}$, \\ Carlo Banfi ${ }^{2,3,+}$ and Karim Bendjelid ${ }^{1,2,+}$ (D)
}

1 Intensive Care Unit, Geneva University Hospitals, 1205 Geneva, Switzerland; matthieu.laurencet@gmail.com (M.L.); benjamin.assouline@hcuge.ch (B.A.); amandine.decharriere@hcuge.ch (A.D.C.); Karim.Bendjelid@hcuge.ch (K.B.)

2 Geneva Hemodynamic Research Group, Faculty of Medicine, University of Geneva, 1205 Geneva, Switzerland; carbanfi@gmail.com

3 Department of Cardio-Thoracic Surgery Istituto Clinico Sant'Ambrogio, Gruppo Ospedaliero San Donato, Milan, and Chair of Cardiac Surgery, University of Milan, 20122 Milan, Italy

* Correspondence: Raphael.Giraud@hcuge.ch

+ Contributed equally.

check for updates

Citation: Giraud, R.; Laurencet, M.; Assouline, B.; De Charrière, A.; Banfi, C.; Bendjelid, K. Can VA-ECMO Be Used as an Adequate Treatment in Massive Pulmonary Embolism? J. Clin. Med. 2021, 10, 3376. https:// doi.org/10.3390/jcm10153376

Academic Editor: Emmanuel Andrès

Received: 9 July 2021

Accepted: 28 July 2021

Published: 30 July 2021

Publisher's Note: MDPI stays neutral with regard to jurisdictional claims in published maps and institutional affiliations.

Copyright: (c) 2021 by the authors. Licensee MDPI, Basel, Switzerland. This article is an open access article distributed under the terms and conditions of the Creative Commons Attribution (CC BY) license (https:// creativecommons.org/licenses/by/ $4.0 /)$.

\begin{abstract}
Introduction: Massive acute pulmonary embolism (MAPE) with obstructive cardiogenic shock is associated with a mortality rate of more than $50 \%$. Venoarterial extracorporeal membrane oxygenation (VA-ECMO) has been increasingly used in refractory cardiogenic shock with very good results. In MAPE, although it is currently recommended as part of initial resuscitation, it is not yet considered a stand-alone therapy. Material and Methods: All patients with MAPE requiring the establishment of VA-ECMO and admitted to our tertiary intensive care unit were analysed over a period of 10 years. The characteristics of these patients, before, during and after ECMO were extracted and analysed. Results: A total of 36 patients were included in the present retrospective study. Overall survival was $64 \%$. In the majority of cases, the haemodynamic and respiratory status of the patient improved significantly within the first $24 \mathrm{~h}$ on ECMO. The 30-day survival significantly increased when ECMO was used as stand-alone therapy (odds ratio (OR) 15.58, 95\% confidence interval (CI) 2.65-91.57, $p=0.002$ ). Nevertheless, when ECMO was implanted following the failure of thrombolysis, the bleeding complications were major $(17(100 \%)$ vs. $1(5.3 \%)$ patients, $p<0.001)$ and the 30-day mortality increased significantly (OR 0.11, 95\% CI 0.022-0.520, $p=0.006$ ). Conclusions: The present retrospective study is certainly one of the most important in terms of the number of patients with MAPE and shock treated with VA-ECMO. This short-term mechanical circulatory support, used as a stand-alone therapy in MAPE, allows for the optimal stabilisation of patients.
\end{abstract}

Keywords: massive acute pulmonary embolism; cardiogenic shock; VA-ECMO; thrombolysis

\section{Introduction}

Massive acute pulmonary embolism (MAPE), defined as pulmonary embolism (PE) with sustained arterial hypotension, is associated with a high mortality rate, up to $50 \%$ [1] The primary cause of death in MAPE is acute right ventricular failure, which induces obstructive cardiogenic shock with low systemic output. In parallel with haemodynamic and respiratory resuscitation, the treatment of MAPE consists of anticoagulation combined with reperfusion therapy.

The 2019 Guidelines of the European Society of Cardiology on the diagnosis and management of acute PE advise the use of systemic thrombolysis as a primary reperfusion therapy. In the case of contraindications to thrombolysis or the failure thereof, it is recommended to undertake surgical embolectomy (SE) or percutaneous catheter-directed treatment [2]. Venoarterial extracorporeal membrane oxygenation (VA-ECMO) may be helpful in patients with MAPE and circulatory collapse or cardiac arrest, but its use as a 
stand-alone technique with anticoagulation remains controversial and should be associated with a reperfusion therapy, such as SE [3].

There are several aetiologies of heart failure that are bearable with VA-ECMO. These can be broadly classified into severe and refractory forms of cardiogenic shock [4], cardiac arrest [5], refractory ventricular arrhythmias [6], acute myocarditis [7] and acute or decompensated right ventricular (RV) heart failure (as with MAPE) [8-12]. In MAPE, case series and cohort studies have reported that ECMO has been used as a replacement, as a complement or as a rescue technique serving as a bridge to reperfusion therapy. However, due to contraindications or major clinical instability, some patients do not lend themselves to reperfusion therapy or do not improve after this treatment [13-15].

VA-ECMO is one of the most reliable and fastest ways to reduce RV overload, improve RV function and haemodynamic status and restore tissue perfusion. Some authors have suggested that VA-ECMO might be used alone until preventive treatment with heparin and spontaneous endogenous thrombolysis to permit the weaning of supportive therapy $[9,15]$.

We hereby present a retrospective cohort of patients with MAPE who were treated with VA-ECMO alone as a part of advanced life support or as a rescue treatment after a failed attempt at systemic thrombolysis and/or catheter thromboaspiration. We hypothesised that ECMO support, associated with therapeutic heparinisation, is a satisfactory treatment for MAPE.

\section{Material and Method}

\subsection{Patients}

We retrospectively analysed a cohort of patients referred to our 36-bed ICU with MAPE, which was diagnosed according to the diagnostic strategy of the European Society of Cardiology guidelines, who needed VA-ECMO support [16]. The patients were selected with the following criteria: at least 18 years old, presenting with acute PE and haemodynamic instability, under vasopressor support or undergoing thrombolysis, and between 2010 and 2019. The patients received either the standard therapy and ECMO support or ECMO support only. The data were manually extracted from the digital records of patients from the Geneva University Hospitals. The inotrope score (12) (IS) and the sequential organ failure assessment (SOFA) score were computed directly from the Patient Data Management System (Centricity Critical Care, Clinisoft, GE HealthCare, General Electric Company, Chicago, IL, USA). This study and its protocol have been approved by the Regional Research Ethics Committee (CCER 2017-00460). Informed consent was not deemed necessary given the nature of the present analyses.

\subsection{Criteria for VA-ECMO Implantation}

The criteria for VA-ECMO implantation in the setting of MAPE were decided by pulmonary embolism response teams (PERTs), including intensivists, cardiac surgeons, cardiologist, anaesthesiologists and angiologists, and are as followings: 1. refractory cardiogenic shock, defined as evidence of tissue hypoxia (e.g., elevated blood lactate or extensive skin mottling) despite adequate volemia; severe RV failure, defined as low cardiac output syndrome associated with echocardiographic signs of $\mathrm{RV}$ dilation, $\mathrm{RV} / \mathrm{LV}$ dimension ration $>1.5$ and septal flattering; low cardiac index $\left(\leq 2.1 \mathrm{~L} / \mathrm{min} / \mathrm{m}^{2}\right)$ under inotropes; sustained hypotension despite high-dose vasoactive drug infusion (norepinephrine $\geq 0.3 \mu \mathrm{g} / \mathrm{kg} / \mathrm{min}$, epinephrine $\geq 0.3 \mu \mathrm{g} / \mathrm{kg} / \mathrm{min}$ or dobutamine $\geq 10 \mu \mathrm{g} / \mathrm{kg} / \mathrm{min}$ ); or 2 . refractory cardiac arrest (no ROSC after $30 \mathrm{~min}$ of advanced resuscitation) with no-flow time below $5 \mathrm{~min}$, low-flow time below $100 \mathrm{~min}$, or effective external chest compressions with an end-tidal $\mathrm{CO}_{2}$ $\left(\mathrm{EtCO}_{2}\right)>1.5 \mathrm{kPa}$. ECMO exclusion criteria were age $>80$ years old, malignancies with poor prognosis within 2 years or irreversible and disabling neurological pathologies and decisions to limit therapeutic interventions. 


\subsection{VA-ECMO Cannulation and Management}

VA-ECMO was percutaneously or surgically implanted by trained intensivists, interventional cardiologists or cardiovascular surgeons with femoro-femoral cannulae from 25 to 28 French for the venous cannula and from 17 to 21 French for the arterial cannula, as previously described [17]. An additional 6- to 7-French catheter was systematically inserted into the superficial femoral artery to perfuse the lower leg and prevent tissue ischaemia. In the case of highly unstable and non-transportable patients, our mobile ECMO team travelled to primary care hospitals with a portable ECMO system, implanted the device at bedside in the ICU and transported the patient to our ICU [18]. The ECMO pump speed was adjusted to obtain blood flow between 3.5 and $5 \mathrm{~L} / \mathrm{min}$ and therapeutic anticoagulation was perfused with intravenous UHF to maintain an anti-factor Xa (anti-Xa) level between 0.3 and $0.6 \mathrm{UI} / \mathrm{L}$.

\subsection{Data Collection}

After ICU admission, the following variables were collected: demographics (age, gender, and body mass index); simplified acute physiology score (SAPS) II; haemodynamic status before intervention (cardiac arrest, no-flow and low-flow times, pre-intervention systolic blood pressure, mean blood pressure, heart rate and IS and shock onset-to-intervention interval); blood gas analyses $\left(\mathrm{pH}\right.$, blood lactate and bicarbonate levels and $\mathrm{PaO}_{2} / \mathrm{FiO}_{2}$ ratio); general blood analyses (creatinine, aspartate and alanine aminotransferases, prothrombin time and factor V activity); specific markers of cardiac function (NT-proBNP or pro-BNP and troponin I or troponin T); radiographic exams (ultrasound and computed tomography (CT)); sonographic findings, if any (RV dilation, pulmonary thrombus visible, left ventricular ejection fraction and tricuspid annular plane systolic excursion); chest CT findings, if any (proximal PE, pulmonary infarction and right ventricle-to-left ventricle diameter ratio); and previous reperfusion therapeutic interventions, if any (systemic fibrinolytic therapy, surgical thrombectomy, catheter-directed thromboaspiration, pulmonary angioplasty and surgical endarterectomy). After $24 \mathrm{~h}$, the IS, $\mathrm{pH}$ and blood lactate levels were extracted. At discharge from the ICU, the quantity of blood products transfused during the ICU stay (packed red blood cells (PRBC), fresh frozen plasma (FFP) and thrombocytes) were also extracted. Mechanical ventilation duration, ICU and hospital lengths of stay and mortality at 30 days were also obtained. Average ECMO blood flow during the first $24 \mathrm{~h}$, as well as ECMO duration, ECMO-related complications and post-ECMO information, were collected. Bleeding complications were reported using the global utilisation of streptokinase and TPA for occluded arteries (GUSTO) classification [19]. Severe lifethreatening haemorrhage was defined as intracerebral bleeding or bleeding resulting in substantial haemodynamic compromise requiring treatment (GUSTO 1). GUSTO 2 defined moderate bleeding as the need for transfusion, whereas GUSTO 3 referred to other bleeding, not requiring transfusion or causing haemodynamic compromise.

Finally, for survivors, at one year, the presence or absence of chronic dyspnoea or chronic thromboembolic pulmonary hypertension (CTEPH) were determined and collected.

\subsection{Statistical Analyses}

Results are presented as median and interquartile ranges (IQR) or numbers with percentages. Continuous variables were compared using the nonparametric Mann-Whitney U test or Wilcoxon signed-rank test as appropriate. Categorical variables were analysed with Fischer's exact test or the Chi-squared test as appropriate. Logistic regression analysis was performed to determine independent predictors associated with 30-day survival. Variables with significant associations using univariate analysis $(p<0.05)$ were entered into the multivariate analysis. Odds ratios (OR) and $95 \%$ confidence intervals $(\mathrm{CI})$ were also calculated. Kaplan-Meier curves for the 30-day survival of patients with MAPE implanted with only an ECMO standalone or treated with fibrinolysis and/or catheter thromboaspiration before ECMO implantation were compared with a log-rank test and a Cox proportional hazards model. Statistical analyses were performed with STATA (StataCorp. 2019. Stata Statistical 
Software: Release 16. College Station, TX, USA: StataCorp LLC.), and a two-sided $p<0.05$ was considered significant.

\section{Results}

During the 10-year period of the study, 36 patients (27 males (75\%); median age 57 (IQR 23)) presenting with MAPE received VA-ECMO. Table 1 displays the description of the complete cohort. Thirty $(83.3 \%)$ patients had predisposing factors for venous thromboembolism. Twenty-two $(61.7 \%)$ patients presented with cardiac arrest-all with a no-flow time of zero minutes and a low-flow time of $28 \pm 30 \mathrm{~min}$. Thirteen (36.1\%) patients received $\mathrm{ECMO}$ as part of advanced cardiopulmonary resuscitation (eCPR). Accordingly, before ECMO institution, both median systolic arterial (74 mmHg (IQR 54)) and mean arterial (59 mmHg (IQR 35)) blood pressures were low. Mean values for the acid-base balance status reflected this situation with a low $\mathrm{pH}(7.08$ (IQR 0.38)), high blood lactate $(8.3 \mathrm{mmol} / \mathrm{L}$ (IQR 11.1)) and low bicarbonate (15.2 $\mathrm{mmol} / \mathrm{L}$ (IQR 8)).

Table 1. Description of the study population.

\begin{tabular}{|c|c|}
\hline Variables & $n=36$ \\
\hline Age, years, median \pm interquartile range (IQR) & $57(23)$ \\
\hline Male, $n(\%)$ & $27(75)$ \\
\hline BMI, $\mathrm{kg} / \mathrm{m}^{2}$, median (IQR) & $27.8(6.3)$ \\
\hline \multicolumn{2}{|l|}{ Comorbidities, $n(\%)$} \\
\hline None & $5(14)$ \\
\hline Postoperative (orthopaedic/visceral/other surgery/polytraumatism) & $18(50)$ \\
\hline Medical (HBP, CKI, obesity) & $5(13.9)$ \\
\hline Recent stroke (ischemic or haemorrhagic) & $3(8.3)$ \\
\hline Other & $5(13.9)$ \\
\hline \multicolumn{2}{|l|}{ Pre-ECMO } \\
\hline Cardiac arrest, $n(\%)$ & $22(61.1)$ \\
\hline Systemic fibrinolytic therapy, $n(\%)$ & $16(44.4)$ \\
\hline Catheter-directed thromboaspiration, $n(\%)$ & $5(13.9)$ \\
\hline No-flow time, min, median (IQR) & $0(0)$ \\
\hline Low-flow time, min, median (IQR) & $17.5(52)$ \\
\hline Systolic blood pressure, $\mathrm{mmHg}$, median (IQR) & $76(54)$ \\
\hline Mean blood pressure, $\mathrm{mmHg}$, median (IQR) & $59(35)$ \\
\hline Heart rate, bpm, median (IQR) & $108(47)$ \\
\hline $\mathrm{pH}$, median (IQR) & $7.08(0.38)$ \\
\hline Blood lactate, mmol/L, median (IQR) & $8.3(11.1)$ \\
\hline Bicarbonate, $\mathrm{mmol} / \mathrm{L}$, median (IQR) & $15.2(8)$ \\
\hline $\mathrm{PaO}_{2} / \mathrm{FiO}_{2}$ ratio, $\mathrm{mmHg}$, median (IQR) & $69(28)$ \\
\hline Creatinine, $\mu \mathrm{mol} / \mathrm{L}$, median (IQR) & $127(62)$ \\
\hline ASAT, U/L, median (IQR) & $219(416)$ \\
\hline ALAT, U/L, median (IQR) & $171(377)$ \\
\hline Quick, \%, median (IQR) & $52(47)$ \\
\hline Cardiac echocardiography, $n(\%)$ & $36(100)$ \\
\hline RV dilation, $n(\%)$ & $36(100)$ \\
\hline $\mathrm{RV} / \mathrm{LV}$ dimensions ratio, $\mathrm{cm}$, median (IQR) & $2.1(0.6)$ \\
\hline TAPSE, mm, median (IQR) & $8(5.2)$ \\
\hline Chest CT-Scan, $n(\%)$ & $9(25)$ \\
\hline Surgical thrombectomy, $n(\%)$ & $0(0)$ \\
\hline ECMO during cardiopulmonary resuscitation $n(\%)$ & $13(36.1)$ \\
\hline Inotrope score at ECMO cannulation, $\mu \mathrm{g} / \mathrm{kg} / \mathrm{min}$, median (IQR) & $49(98)$ \\
\hline Shock onset-to-ECMO interval, hours, median (IQR) & $1(1.5)$ \\
\hline Femoral-femoral VA-ECMO, $n(\%)$ & $36(100)$ \\
\hline Percutaneous VA-ECMO, $n(\%)$ & $25(69.4)$ \\
\hline Thrombolysis contraindication, $n(\%)$ & $21(58.3)$ \\
\hline SAPS II at ICU admission, median (IQR) & $68(38)$ \\
\hline
\end{tabular}


Table 1. Cont.

\begin{tabular}{lc}
\hline \multicolumn{1}{c}{ Variables } & $n=36$ \\
\hline One year follow-up & $1(2.8)$ \\
Chronic dyspnoea $n(\%)$ & $0(0)$ \\
Chronic thromboembolic pulmonary hypertension $n(\%)$ & $1(2.8)$ \\
Pulmonary angioplasty, $n(\%)$ & $1(2.8)$ \\
Surgical endarterectomy, $n(\%)$ & \\
\hline
\end{tabular}

HBP: high blood pressure, CKI: chronic kidney injury, ASAT, aspartate aminotransferase, ALAT: alanine aminotransferase, RV: right ventricle, LV: left ventricle, TAPSE: tricuspid annular plane systolic excursion.

All patients had cardiac echocardiography, whereas chest CT was only performed in nine $(25 \%)$ patients, as the majority were too unstable for a radiographic exam. In the cohort, RV dilation, which is an indicator of elevated risk of short-term mortality, was found in all patients. For patients who were too unstable, thoracic CT angiography was performed a posteriori with assistance and confirming the diagnosis of $\mathrm{PE}$ in all cases.

The installation of the ECMO was carried out relatively quickly, since the onset of shock to the ECMO interval was $1 \mathrm{~h}$ (IQR 1.5). At ECMO cannulation, the median SAPS II score and IS were high, as all patients required haemodynamic support with vasoactive drugs.

Reperfusion therapy with systemic thrombolysis was undertaken in $16(44.4 \%)$ patients, whereas 21 (58.3\%) patients had contraindications to thrombolysis. Five (15.6\%) patients benefited from catheter-directed thromboaspiration and none underwent surgical thrombectomy, as this latest therapy is not implemented in our hospital. All patients received peripheral femoro-femoral VA-ECMO, including $25(69.4 \%)$ patients percutaneously.

As described in Table 2, $24 \mathrm{~h}$ on ECMO rapidly corrected $\mathrm{pH}$, blood lactate level and IS (Figure 1).

Table 2. $\mathrm{pH}$, Blood lactate and inotrope score evolution before and $24 \mathrm{~h}$ after ECMO.

\begin{tabular}{lccc}
\hline \multicolumn{1}{c}{ Timing } & $\begin{array}{c}\text { Pre- } \\
\text { ECMO }\end{array}$ & $\begin{array}{c}\text { After 24 h on } \\
\text { ECMO }\end{array}$ & $p$-Value \\
\hline $\mathrm{pH}$, median $(\mathrm{IQR})$ & $7.08(0.38)$ & $7.43(0.1)$ & $<0.001^{1}$ \\
Blood lactate, $\mathrm{mmol} / \mathrm{L}$, median (IQR) & $8.3(11.1)$ & $1.1(0.9)$ & $<0.001^{1}$ \\
Inotrope score, $\mu \mathrm{g} / \mathrm{kg} / \mathrm{min}$, median (IQR) & $49(98)$ & $0(10)$ & $<0.001^{1}$ \\
\hline
\end{tabular}

${ }^{1}$ Wilcoxon Signed Ranks Test.

Table 3 describes the ICU events and outcomes among ECMO-treated patients with MAPE according to 30-day survival status. When comparing non-survivors to survivors, significantly higher SAPS II scores, pre-ECMO IS and IS after $24 \mathrm{~h}$ of ECMO were found in non-survivors. ECMO duration and both ICU and hospital lengths of stay were shorter among non-survivors. For in-ICU ECMO-related complications, haemorrhage levels and PRBC units transfused were also significantly higher in non-survivors. 


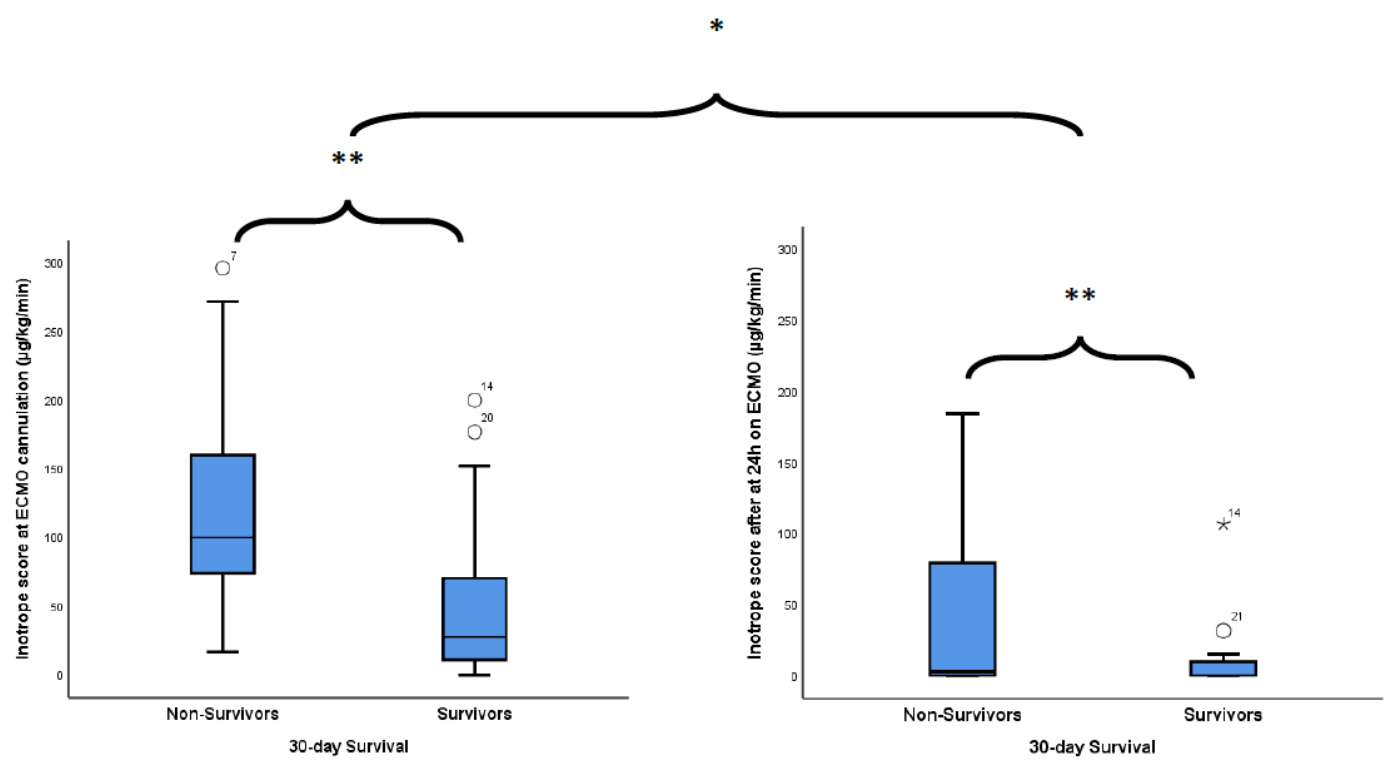

Figure 1. Inotrope score change between pre and post-VA-ECMO cannulation according to patients' 30-day status. ${ }^{*} p<0.001$ between pre-ECMO and after $24 \mathrm{~h}$ on ECMO, ${ }^{* *} p=0.004$ between survivors and non-survivors.

Table 3. ICU events and outcomes among ECMO-treated patients for massive PE according to 30-day survival status.

\begin{tabular}{|c|c|c|c|c|}
\hline Variables & $\begin{array}{l}\text { All Patients } \\
\quad(n=36)\end{array}$ & $\begin{array}{c}\text { Non-Survivors } \\
(n=13)\end{array}$ & $\begin{array}{c}\text { Survivors } \\
(n=23)\end{array}$ & $p$-Value \\
\hline \multicolumn{5}{|l|}{ Pre-ECMO } \\
\hline Inotrope score, $\mu \mathrm{g} / \mathrm{kg} / \mathrm{min}$, median (IQR) & $49(98)$ & $100(86)$ & $28(60)$ & $0.004^{1}$ \\
\hline Thrombolysis, $n(\%)$ & $13(36.1)$ & $10(76.9)$ & $6(26.1)$ & 0.005 \\
\hline pH, median (IQR) & $7.08(0.38)$ & $6.99(0.31)$ & $7.12(0.42)$ & $0.055^{1}$ \\
\hline Blood lactate, mmol/L, median (IQR) & $8.3(11.1)$ & $13.8(8.5)$ & $4.2(8.6)$ & $0.008^{1}$ \\
\hline Bicarbonate, mmol/L, median (IQR) & $15.2(8)$ & $11(7.1)$ & $17.1(7.2)$ & $0.018^{1}$ \\
\hline $\mathrm{PaO}_{2} / \mathrm{FiO}_{2}, \mathrm{mmHg}$, median (IQR) & $69(28)$ & $61(19)$ & $73(37)$ & $0.415^{1}$ \\
\hline Creatinine, $\mu \mathrm{mol} / \mathrm{L}$, median (IQR) & $127(62)$ & $137(77)$ & $124(47)$ & $0.214^{1}$ \\
\hline ASAT, U/L, median (IQR) & 219 (416) & $342(538)$ & $125(305)$ & $0.015^{1}$ \\
\hline ALAT, U/L, median (IQR) & $171(377)$ & $309(398)$ & $102(243)$ & $0.026^{1}$ \\
\hline Quick, \%, median (IQR) & $52(47)$ & $43(27)$ & $57(52)$ & $0.034^{1}$ \\
\hline TAPSE, mm, median (IQR) & $8(5.2)$ & $8(5)$ & $8.1(4.5)$ & $0.922^{1}$ \\
\hline $\mathrm{RV} / \mathrm{LV}$ dimension ratio, median (IQR) & $2.1(0.6)$ & $2.32(0.84)$ & $2.1(0.36)$ & $0.626^{1}$ \\
\hline No-flow time, min,median (IQR) & $0(0)$ & $0(0)$ & $0(0)$ & 1.000 \\
\hline Low-flow time, min,median (IQR) & $17.5(52)$ & $50(30)$ & $0(25)$ & $0.002^{1}$ \\
\hline $\begin{array}{l}\text { ECMO during cardiopulmonary resuscitation (vs. } \\
\text { not), } n(\%)\end{array}$ & $13(36.1)$ & $8(61.5)$ & $5(21.7)$ & $0.030^{3}$ \\
\hline SAPS II at ICU admission, median (IQR) & $68(38)$ & 75 (19) & $55(42)$ & $0.020^{1}$ \\
\hline $\begin{array}{c}\text { Inotrope score after } 24 \mathrm{~h} \text { of ECMO, } \mu \mathrm{g} / \mathrm{kg} / \mathrm{min}, \\
\text { median (IQR) }\end{array}$ & 49 (98) & $3(44)$ & 0 (10) & $0.004^{1}$ \\
\hline \multicolumn{5}{|l|}{ In-ICU complications, $n(\%)$} \\
\hline Haemorrhage & $18(50)$ & $12(92.3)$ & $6(26.1)$ & $<0.001^{3}$ \\
\hline Stroke & $4(11.1)$ & $1(7.7)$ & $3(13)$ & $0.541^{2}$ \\
\hline Infection & $3(8.33)$ & $1(7.7)$ & $2(8.7)$ & $0.709^{2}$ \\
\hline Packed red-cell units transfused, $n$, median (IQR) & $4.5(8.5)$ & $8(7)$ & $0(5)$ & $0.003^{1}$ \\
\hline Fresh-frozen plasma units transfused, $n$, mean \pm SD & $1(4)$ & $5(11)$ & $0(2)$ & $0.012^{1}$ \\
\hline Platelets transfused, $n$, mean $\pm \mathrm{SD}$ & $1(5)$ & $0(1)$ & $0(0)$ & $0.253^{1}$ \\
\hline ECMO duration, days, mean \pm SD & $3.2(3.2)$ & $1(1.3)$ & $4(2.4)$ & $<0.001^{1}$ \\
\hline MV duration, days, median (IQR) & $2.4(10.5)$ & $1(1.3)$ & $8(14)$ & $0.149^{1}$ \\
\hline ICU LOS, days, median (IQR) & $8.7(16)$ & $1.2(1.9)$ & $15.8(13.4)$ & $<0.001^{1}$ \\
\hline Hospital LOS, days, median (IQR) & $15(36)$ & $1.3(2)$ & $30(44.5)$ & $<0.001^{1}$ \\
\hline
\end{tabular}

${ }^{1}$ For continuous variables, nonparametric Mann-Whitney test; ${ }^{2}$ for categorical variables, Fischer exact test; ${ }^{3}$ Chi-squared test. Bold has been used to highlight the variables statiscally significant. 
The variables independently associated with 30-day survival status among ECMOtreated patients are presented in Table 4. A univariate analysis showed that ECMO as a standalone therapy was highly associated with 30-day survival (OR 15.58, 95\% CI 2.65-91.57, $p=0.002$ ). However, thrombolysis failure, ECMO during cardiopulmonary resuscitation vs. not, ECMO and fibrinolytic treatment or catheter-directed thromboaspiration vs. ECMO alone and the presence of cardiac arrest before ECMO initiation vs. not were found to significantly increase the risk of death.

Table 4. Variables independently associated with 30-day survival status among ECMO-treated patients for massive PE.

\begin{tabular}{cccc}
\hline Variables & OR & $\mathbf{9 5 \% C I}$ & $p$-Value $\mathbf{1}^{\mathbf{1}}$ \\
\hline $\begin{array}{c}\text { ECMO only (vs ECMO + thrombolysis } \\
\text { or catheter directed thromboaspiration) }\end{array}$ & 15.583 & $2.652-91.572$ & 0.002 \\
$\quad \begin{array}{c}\text { Thrombolysis failure } \\
\text { ECMO during cardiopulmonary }\end{array}$ & 0.106 & $0.022-0.520$ & 0.006 \\
$\begin{array}{c}\text { resuscitation (vs. not) } \\
\text { Pre-ECMO cardia arrest (vs. not) }\end{array}$ & 0.174 & $0.039-0.773$ & 0.022 \\
\hline
\end{tabular}

${ }^{1}$ Logistic regression model.

ECMO-related complications and 30-day survival status, compared between patients treated with ECMO only vs. patients who received ECMO + fibrinolytic treatment, are presented in Table 5. Haemorrhaging was significantly higher in patients receiving $\mathrm{ECMO}+$ fibrinolytic or catheter-directed thromboaspiration vs. ECMO alone. Thirtyday mortality was also significantly higher in patients receiving ECMO + fibrinolytic or catheter-directed thromboaspiration vs. ECMO alone.

Table 5. ICU events (complications) and 30-day survival status between ECMO-treated patients for massive PE versus ECMO + fibrinolytic therapy.

\begin{tabular}{|c|c|c|c|}
\hline Outcomes & $\begin{array}{l}\text { ECMO Only } \\
\quad(n=19)\end{array}$ & $\begin{array}{c}\text { ECMO + Fibrinolytic or } \\
\text { Catheter-Directed } \\
\text { Thromboaspiration }(n=17)\end{array}$ & $p$-Value \\
\hline \multicolumn{4}{|l|}{ In-ICU complications, $n(\%)$} \\
\hline Haemorrhage & $1(5.3)$ & $17(100)$ & $<0.001^{1}$ \\
\hline Stroke & $2(10.5)$ & $2(11.8)$ & $1.000^{2}$ \\
\hline Infection & $1(5.3)$ & $2(11.8)$ & $0.593^{2}$ \\
\hline Anoxic encephalopathy & $4(28.6)$ & $10(71.4)$ & $0.039^{2}$ \\
\hline 30-day death status, $n(\%)$ & $2(10.5)$ & $11(64.7)$ & $0.001^{1}$ \\
\hline
\end{tabular}

${ }^{1}$ Chi-2 test; ${ }^{2}$ Fischer exact test.

Kaplan-Meier curves of patients with MAPE implanted with only an ECMO standalone or treated with fibrinolysis and/or catheter thromboaspiration before ECMO implantation showed a significant difference in 30-day survival (Cox proportional hazards model: $p=0.004$, HR 8.563 (95\% CI 2.775-25.76) (Figure 2). 


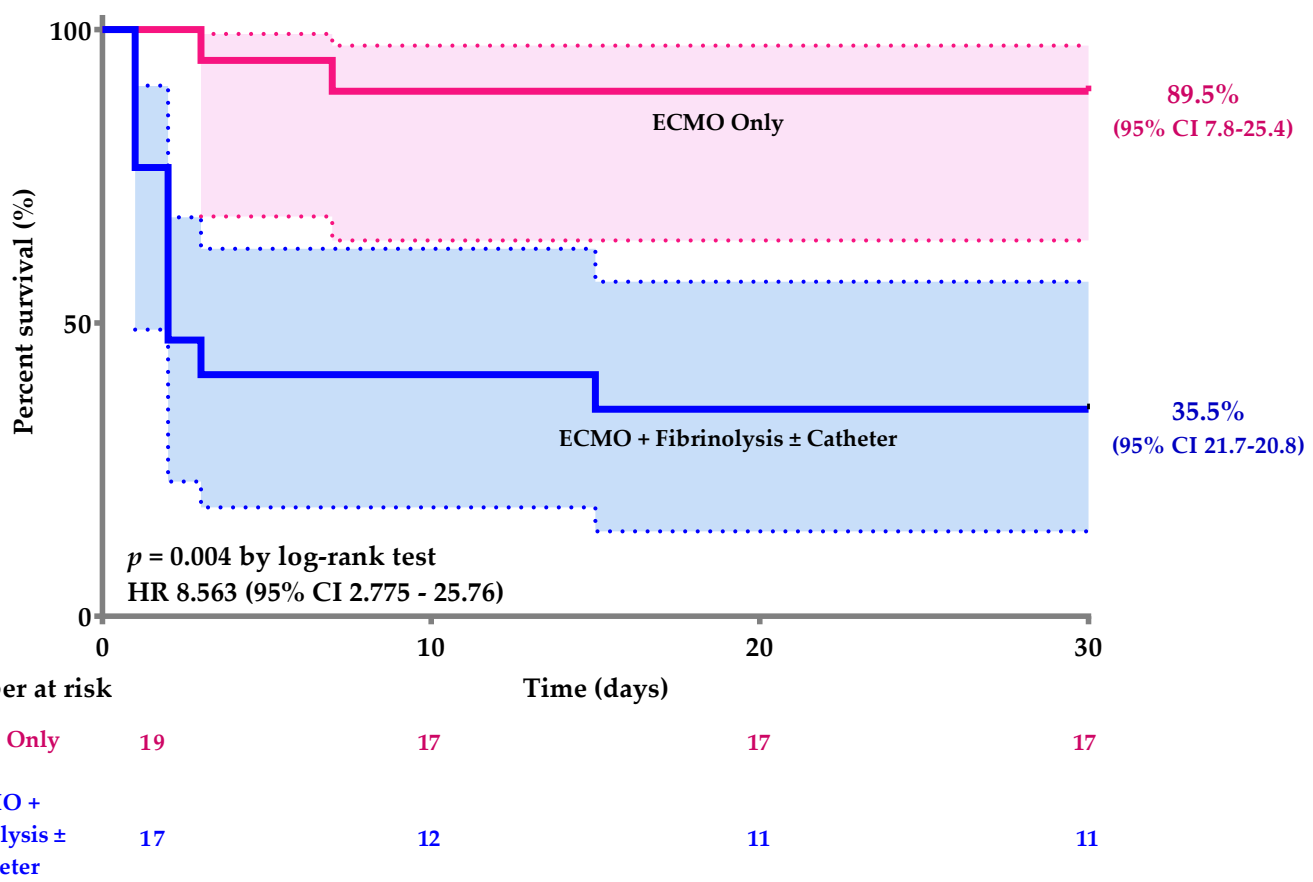

Figure 2. Kaplan-Meier curves for the 30-day survival of patients with MAPE implanted with only an ECMO or treated with fibrinolysis and/or catheter thromboaspiration before ECMO implantation. HR: Hazard Ratio.

Finally, all patients with anoxic encephalopathy in relation to cardiac arrest died. At the one-year follow-up, only one patient $(2.8 \%)$ was diagnosed with chronic dyspnoea and one patient $(2.8 \%)$ had CTEPH.

\section{Discussion}

To our knowledge, this is one of the largest follow-up studies on life-threatening MAPE treated with VA-ECMO. The main finding of the present study is that ECMO as a standalone therapy for MAPE is associated with a decrease in 30-day mortality in comparison with ECMO + fibrinolytic or catheter-directed thromboaspiration. Moreover, ECMO during cardiopulmonary resuscitation and pre-ECMO cardiac arrest with ROSC are both associated with an increase in 30-day mortality. Finally, the association of ECMO + fibrinolytic or catheter-directed thromboaspiration is correlated with more haemorrhagic complications compared with ECMO as a stand-alone therapy for MAPE.

In MAPE, mechanical obstruction due to thrombus present in the pulmonary arteries, associated with hypoxic pulmonary vasoconstriction and the release of vasoconstrictor mediators, leads to a sharp increase in the RV afterload [13]. It results in dilation with subsequent RV failure and a deviation of the intraventricular septum to the disadvantage of the left ventricle with a decrease in its preload and a drop in cardiac output, inducing cardiogenic shock with hypotension and hypoperfusion of tissues, as well as cardiac arrest in some cases $[20,21]$. In parallel with the haemodynamic impairment, MAPE induces respiratory failure. A low level of cardiac output causes desaturation of mixed venous blood. Areas of reduced flow in the obstructed pulmonary arteries, associated with areas of overflow in the capillary bed served by unobstructed pulmonary vessels, cause a ventilation/perfusion mismatch, which contributes to hypoxaemia [22] and an increase in dead space. ECMO is now recommended by the latest Guidelines of the European Society of Cardiology (ESC) as a temporary mechanical circulatory support in patients with MAPE and circulatory collapse or cardiac arrest [2], offering full cardiopulmonary support [23], as shown by our results. Indeed, $\mathrm{pH}$, blood lactate level and IS significantly improved $24 \mathrm{~h}$ after ECMO implantation.

Although no RCTs testing the efficacy and safety of these devices in the context of MAPE have been conducted to date, the survival of critically ill patients has been described 
in a number of case series $[3,9,12,24-26]$. The main explanation given is that ECMO is associated with a high incidence of complications, particularly an increased risk of bleeding related to the need for vascular access and mostly in patients in whom systemic thrombolysis failed. The latter is confirmed by our study. However, our results did not show more haemorrhagic complications (22\%) compared with a study evaluating 304 patients from the International Cooperative Pulmonary Embolism Registry who received fibrinolysis, showing that 66 patients (21.7\%) had major bleeding [27], or data from a tertiary centre in Paris, showing that of 132 patients receiving thrombolysis, 33 (25\%) experienced major bleeding [28].

For many years, the recommended reperfusion therapy for PE has been systemic thrombolysis, with IB-level evidence [2,13]. In the latest meta-analysis, on which most of these recommendations are based, only four studies included patients with MAPE [29]. Among these, three were published before 1980. The most recent study included in the meta-analysis dates from 1995 and included only eight patients [30]. Although the results showed that the four patients who received streptokinase survived, whereas the four patients who received heparin died, no conclusion or recommendations can be made, neither on the basis of this study nor on the results of the meta-analysis concerning patients with shock and MAPE. In addition, most studies support the fact that systemic thrombolysis increases the risk of bleeding, particularly in patients with cardiogenic shock and cardiac arrest [29], except a recent systematic review about 301 patients, showing that 51 patients who received systemic thrombolysis prior to cannulation had similar survival compared with patients who did not ( $67 \%$ vs. $61 \%$, respectively; $p=0.48)$ [31].

Thrombolysis, in addition to having many contraindications, is not always effective. In our study, 21 (58.3\%) patients had an absolute contraindication to systemic thrombolysis, and in the other $15(41.6 \%)$ patients, ECMO was implemented in a context of failed thrombolysis. In the $18(50 \%)$ patients in our cohort who presented with bleeding, all had received systemic thrombolysis. Therefore, the failure of thrombolysis appears to be a factor that is directly correlated with an increase in 30-day mortality. In the study by Maggio et al., which included 21 patients (19 of whom had been implanted with VA-ECMO for MAPE), the $11(52 \%)$ patients who underwent treatment before cannulation, such as thrombolytic agents, catheter-based intervention or surgical pulmonary embolectomy, failed. Of these 11 patients, there was only a $45 \%$ survival rate. However, in the 10 patients in whom ECMO was initiated as the primary, initial intervention, there was an $80 \%$ survival rate [8].

Given patient heterogeneity, the multitude of available treatment modalities and the lack of consensus guidelines, treatment strategies for these complex patients with MAPE are often debated. Multidisciplinary pulmonary embolism response teams (PERTs) are dedicated to address this lack of consensus [32]. An analysis among 769 consecutive inpatients with PE was conducted to compare the outcomes of all patients with PE before and after PERT availability. The results showed that PERT-era patients had lower rates of major or clinically relevant non-major bleeding $(17.0 \%$ vs. $8.3 \%, p=0.002)$ and shorter times to therapeutic anticoagulation $(16.3 \mathrm{~h}$ vs. $12.6 \mathrm{~h}, p=0.009)$. There was also a significant decrease in 30-day/inpatient mortality ( $8.5 \%$ vs. $4.7 \%, p=0.03)$, particularly in patients with MAPE (mortality $10.0 \%$ vs. $5.3 \%, p=0.02$ ) [33]. As in our centre, the availability of multidisciplinary PERT certainly allows improved outcomes, including 30-day mortality.

Despite very strict implantation criteria (all the patients in this study had, in particular, a no-flow time of $0 \mathrm{~min}$ ), the occurrence of cardiac arrest in the context of a massive PE has a poor prognosis. In a consecutive cohort of thirteen patients with confirmed MAPE for whom PERT was activated and selected patients treated with ECMO confirmed that patients with MAPE who suffer a cardiac arrest have high morbidity and mortality [34]. This was confirmed in a systematic review, in which multivariate analysis showed a six-fold increase in the risk of death if cannulation occurred during cardiopulmonary resuscitation (adjusted odds ratio, 5.67; $p=0.03$ ) [31]. The current recommendations emphasise that starting a high-quality cardiac massage as quickly as possible influences the effectiveness of all other interventions [35]. Therefore, it is essential that CPR be started immediately 
after the collapse in order to keep the no-flow period to a minimum. It is therefore essential that the CPR is of good quality during the low-flow period [14,23]. To ensure this, it is recommended to monitor expired $\mathrm{CO}_{2}\left(\mathrm{EtCO}_{2}\right)$, which is a validated predictor of survival in CA [13].

In our study, no patient underwent surgical embolectomy; however, our survival results are quite good. As much as it seems reasonable to operate on stable patients, without cardiogenic shock and with a contraindication to thrombolysis, it seems very risky to perform this operation in patients in a state of profound shock who did not respond favourably to thrombolysis with collapsed coagulation factors. Finally, the latest published series emphasises the place of ECMO before this type of intervention, which makes it possible to stabilise patients, to perform surgery in better conditions and to ensure optimal postoperative haemodynamic support [36]. It is therefore questionable whether to perform SE while the patient is stabilised on VA-ECMO with good organ perfusion, rather than waiting for the thrombus and RV failure to resolve thanks to the thrombolytic properties of heparin and to natural endogenous fibrinolysis, allowing the weaning of circulatory support $[9,14]$.

The strength of this study is the number of patients analysed with two treatment options and their descriptions. However, our study also presents some limitations. First, it is a single-centre, retrospective study, focusing only on patients receiving an ECMO in the context of MAPE without comparing them to patients who have been optimally treated with reperfusion therapy. Second, the number of patients included remains limited, thus reducing the power of the statistical analysis. Third, there was no prospective followup after hospital discharge based on long-term cardiac echocardiography and imaging to detect the potential development of CTEPH in the absence of thrombus extraction (by thrombolysis or SE). Further studies focusing on this point are needed to support the longterm safety of an ECMO strategy without additional mechanical clot removal therapies.

\section{Conclusions}

The present retrospective monocentric study is certainly one of the most standardised in terms of the number of patients with MAPE who presented with refractory cardiogenic shock and who were put on VA-ECMO. Overall survival was almost $64 \%$. Our results show that this short-term mechanical circulatory support allows for the optimal stabilisation of severely ill patients. In addition, when used as a stand-alone therapy, it allows for a significant improvement in 30-day survival. Nevertheless, when it is implanted following a failure of thrombolysis, the bleeding complications are major and the 30-day mortality increases significantly. The main causes of death are the ECMO-thrombolysis association, the presence of cardiac arrest and the implementation of ECMO during cardiac arrest. Prospective studies are definitely required in order to clarify the role of ECMO in MAPE.

Author Contributions: R.G. conceived the study; performed the literature search; extracted the data; performed the statistical analysis and participated in the analysis, interpretation and article redaction by critically revising the study protocol and the article draft. M.L. participated in the study conception, wrote the protocol draft, performed the literature search, extracted the data and wrote the article draft. B.A. participated in the study conception, analysis and interpretation and article redaction by critically revising the study protocol and the article draft. A.D.C. participated in the study conception, analysis interpretation and article redaction by critically revising the article draft. C.B. extracted the data and participated to the study conception, analysis and interpretation and article redaction by critically revising the article draft. K.B. participated in the study conception and article redaction by critically revising the study protocol and article draft. All authors have read and agreed to the published version of the manuscript.

Funding: This research received no external funding.

Institutional Review Board Statement: This study and its protocol have been approved by the Regional Research Ethics Committee (CCER 2017-00460). Informed consent was not deemed necessary given the nature of the present analyses. 
Informed Consent Statement: Not applicable.

Data Availability Statement: The datasets used and analysed during the current study are available from the corresponding author on reasonable request.

Acknowledgments: The authors would like to thank Angèle GAYET AGERON for her valuable contribution for the statistical analysis for this study.

Conflicts of Interest: The authors declare that they have no competing interest.

Competency in Medical Knowledge: Massive pulmonary embolism (MAPE) is associated with an increased risk of mortality, related to profound obstructive cardiogenic shock and cardiac arrest. Thrombolysis, a treatment currently recommended in the absence of absolute contraindications, is not always effective and not without risk. Absolute contraindications to fibrinolysis are listed in the 2019 ESC Guidelines for the diagnosis and management of acute pulmonary embolism and include a history of haemorrhagic stroke or stroke of unknown origin; ischaemic stroke in the previous 6 months; central nervous system neoplasm; major trauma, surgery or head injury in the previous 3 weeks; bleeding diathesis and active bleeding. VA-ECMO associated with full anticoagulation allows both the rapid restoration of haemodynamics and thromboembolic disease treatment.

Translational Outlook: Although it remains unclear whether VA-ECMO might be effective as a standalone therapy in MAPE, future randomised studies should be performed to determine its right place.

\section{References}

1. Kucher, N.; Rossi, E.; De Rosa, M.; Goldhaber, S.Z. Massive pulmonary embolism. Circulation 2006, 113, 577-582. [CrossRef]

2. Konstantinides, S.V.; Meyer, G.; Becattini, C.; Bueno, H.; Geersing, G.J.; Harjola, V.P.; Huisman, M.V.; Humbert, M.; Jennings, C.S.; Jimenez, D.; et al. 2019 ESC Guidelines for the diagnosis and management of acute pulmonary embolism developed in collaboration with the European Respiratory Society (ERS). Eur. Heart J. 2020, 41, 543-603. [CrossRef] [PubMed]

3. Meneveau, N.; Guillon, B.; Planquette, B.; Piton, G.; Kimmoun, A.; Gaide-Chevronnay, L.; Aissaoui, N.; Neuschwander, A.; Zogheib, E.; Dupont, H.; et al. Outcomes after extracorporeal membrane oxygenation for the treatment of high-risk pulmonary embolism: A multicentre series of 52 cases. Eur. Heart J. 2018, 39, 4196-4204. [CrossRef] [PubMed]

4. Pineton de Chambrun, M.; Brechot, N.; Combes, A. The place of extracorporeal life support in cardiogenic shock. Curr. Opin. Crit. Care 2020, 26, 424-431. [CrossRef] [PubMed]

5. Kalra, R.; Kosmopoulos, M.; Goslar, T.; Raveendran, G.; Bartos, J.A.; Yannopoulos, D. Extracorporeal cardiopulmonary resuscitation for cardiac arrest. Curr. Opin. Crit. Care 2020, 26, 228-235. [CrossRef] [PubMed]

6. Brunner, M.E.; Siegenthaler, N.; Shah, D.; Licker, M.J.; Cikirikcioglu, M.; Brochard, L.; Bendjelid, K.; Giraud, R. Extracorporeal membrane oxygenation support as bridge to recovery in a patient with electrical storm related cardiogenic shock. Am. J. Emerg. Med. 2013, 31, e461-e466. [CrossRef]

7. Pozzi, M.; Banfi, C.; Grinberg, D.; Koffel, C.; Bendjelid, K.; Robin, J.; Giraud, R.; Obadia, J.F. Veno-arterial extracorporeal membrane oxygenation for cardiogenic shock due to myocarditis in adult patients. J. Thorac. Dis. 2016, 8, E495-E502. [CrossRef]

8. Maggio, P.; Hemmila, M.; Haft, J.; Bartlett, R. Extracorporeal life support for massive pulmonary embolism. J. Trauma 2007, 62, 570-576. [CrossRef]

9. Corsi, F.; Lebreton, G.; Brechot, N.; Hekimian, G.; Nieszkowska, A.; Trouillet, J.L.; Luyt, C.E.; Leprince, P.; Chastre, J.; Combes, A.; et al. Life-threatening massive pulmonary embolism rescued by venoarterial-extracorporeal membrane oxygenation. Crit. Care 2017, 21, 76. [CrossRef]

10. Guliani, S.; Das Gupta, J.; Osofsky, R.; Kraai, E.P.; Mitchell, J.A.; Dettmer, T.S.; Wray, T.C.; Tawil, I.; Rana, M.A.; Marinaro, J. Venoarterial extracorporeal membrane oxygenation is an effective management strategy for massive pulmonary embolism patients. J. Vasc. Surg. Venous Lymphat Disord. 2020, 9, 307-314. [CrossRef]

11. George, B.; Parazino, M.; Omar, H.R.; Davis, G.; Guglin, M.; Gurley, J.; Smyth, S. A retrospective comparison of survivors and non-survivors of massive pulmonary embolism receiving veno-arterial extracorporeal membrane oxygenation support. Resuscitation 2018, 122, 1-5. [CrossRef]

12. Yusuff, H.O.; Zochios, V.; Vuylsteke, A. Extracorporeal membrane oxygenation in acute massive pulmonary embolism: A systematic review. Perfusion 2015, 30, 611-616. [CrossRef]

13. Abraham, P.; Arroyo, D.A.; Giraud, R.; Bounameaux, H.; Bendjelid, K. Understanding haemorrhagic risk following thrombolytic therapy in patients with intermediate-risk and high-risk pulmonary embolism: A hypothesis paper. Open Heart 2018, 5, e000735. [CrossRef]

14. Giraud, R.; Banfi, C.; Siegenthaler, N.; Bendjelid, K. Massive pulmonary embolism leading to cardiac arrest: One pathology, two different ECMO modes to assist patients. J. Clin. Monit. Comput. 2015, 30, 933-937. [CrossRef]

15. Pavlovic, G.; Banfi, C.; Tassaux, D.; Peter, R.E.; Licker, M.J.; Bendjelid, K.; Giraud, R. Peri-operative massive pulmonary embolism management: Is veno-arterial ECMO a therapeutic option? Acta Anaesthesiol. Scand. 2014, 58, 1280-1286. [CrossRef] 
16. Konstantinides, S.V.; Torbicki, A.; Agnelli, G.; Danchin, N.; Fitzmaurice, D.; Galie, N.; Gibbs, J.S.; Huisman, M.V.; Humbert, M.; Kucher, N.; et al. 2014 ESC guidelines on the diagnosis and management of acute pulmonary embolism. Eur. Heart J. 2014, 35, 3033-3069. [CrossRef] [PubMed]

17. Banfi, C.; Pozzi, M.; Brunner, M.E.; Rigamonti, F.; Murith, N.; Mugnai, D.; Obadia, J.F.; Bendjelid, K.; Giraud, R. Veno-arterial extracorporeal membrane oxygenation: An overview of different cannulation techniques. J. Thorac. Dis. 2016, 8, E875-E885. [CrossRef] [PubMed]

18. Moret, M.; Banfi, C.; Sartorius, D.; Fumeaux, T.; Leeman-Refondini, C.; Sologashvili, T.; Reuse, J.; Nowicki, B.; Mamode-Premdjee, J.; Tassaux, D.; et al. [“Mobile” ECMO]. Rev. Med. Suisse 2014, 10, 2368-2370. [PubMed]

19. Investigators, G.A. The effects of tissue plasminogen activator, streptokinase, or both on coronary-artery patency, ventricular function, and survival after acute myocardial infarction. N. Engl. J. Med. 1993, 329, 1615-1622. [CrossRef]

20. Bendjelid, K. Right atrial pressure: Determinant or result of change in venous return? Chest 2005, 128, 3639-3640. [CrossRef]

21. Jaff, M.R.; McMurtry, M.S.; Archer, S.L.; Cushman, M.; Goldenberg, N.; Goldhaber, S.Z.; Jenkins, J.S.; Kline, J.A.; Michaels, A.D.; Thistlethwaite, P.; et al. Management of massive and submassive pulmonary embolism, iliofemoral deep vein thrombosis, and chronic thromboembolic pulmonary hypertension: A scientific statement from the American Heart Association. Circulation 2011, 123, 1788-1830. [CrossRef] [PubMed]

22. Burrowes, K.S.; Clark, A.R.; Tawhai, M.H. Blood flow redistribution and ventilation-perfusion mismatch during embolic pulmonary arterial occlusion. Pulm. Circ. 2011, 1, 365-376. [CrossRef] [PubMed]

23. Tahir, U.A.; Carroll, B.; Pinto, D.S. Massive pulmonary embolism: Embolectomy or extracorporeal membrane oxygenation? Curr. Opin. Crit. Care 2019, 25, 630-637. [CrossRef]

24. Weinberg, A.; Tapson, V.F.; Ramzy, D. Massive Pulmonary Embolism: Extracorporeal Membrane Oxygenation and Surgical Pulmonary Embolectomy. Semin. Respir. Crit. Care Med. 2017, 38, 66-72. [CrossRef]

25. Dolmatova, E.V.; Moazzami, K.; Cocke, T.P.; Elmann, E.; Vaidya, P.; Ng, A.F.; Satya, K.; Narayan, R.L. Extracorporeal Membrane Oxygenation in Massive Pulmonary Embolism. Heart Lung 2017, 46, 106-109. [CrossRef]

26. Swol, J.; Buchwald, D.; Strauch, J.; Schildhauer, T.A. Extracorporeal life support (ECLS) for cardiopulmonary resuscitation (CPR) with pulmonary embolism in surgical-A case series. Perfusion 2016, 31, 54-59. [CrossRef] [PubMed]

27. Goldhaber, S.Z.; Visani, L.; De Rosa, M. Acute pulmonary embolism: Clinical outcomes in the International Cooperative Pulmonary Embolism Registry (ICOPER). Lancet 1999, 353, 1386-1389. [CrossRef]

28. Meyer, G.; Gisselbrecht, M.; Diehl, J.L.; Journois, D.; Sors, H. Incidence and predictors of major hemorrhagic complications from thrombolytic therapy in patients with massive pulmonary embolism. Am. J. Med. 1998, 105, 472-477. [CrossRef]

29. Marti, C.; John, G.; Konstantinides, S.; Combescure, C.; Sanchez, O.; Lankeit, M.; Meyer, G.; Perrier, A. Systemic thrombolytic therapy for acute pulmonary embolism: A systematic review and meta-analysis. Eur. Heart J 2015, 36, 605-614. [CrossRef]

30. Jerjes-Sanchez, C.; Ramirez-Rivera, A.; de Lourdes Garcia, M.; Arriaga-Nava, R.; Valencia, S.; Rosado-Buzzo, A.; Pierzo, J.A.; Rosas, E. Streptokinase and Heparin versus Heparin Alone in Massive Pulmonary Embolism: A Randomized Controlled Trial. J. Thromb. Thrombolysis 1995, 2, 227-229. [CrossRef]

31. Scott, J.H.; Gordon, M.; Vender, R.; Pettigrew, S.; Desai, P.; Marchetti, N.; Mamary, A.J.; Panaro, J.; Cohen, G.; Bashir, R.; et al. Venoarterial Extracorporeal Membrane Oxygenation in Massive Pulmonary Embolism-Related Cardiac Arrest: A Systematic Review. Crit. Care Med. 2021, 49, 760-769. [CrossRef]

32. Kabrhel, C.; Jaff, M.R.; Channick, R.N.; Baker, J.N.; Rosenfield, K. A multidisciplinary pulmonary embolism response team. Chest 2013, 144, 1738-1739. [CrossRef] [PubMed]

33. Chaudhury, P.; Gadre, S.K.; Schneider, E.; Renapurkar, R.D.; Gomes, M.; Haddadin, I.; Heresi, G.A.; Tong, M.Z.; Bartholomew, J.R. Impact of Multidisciplinary Pulmonary Embolism Response Team Availability on Management and Outcomes. Am. J. Cardiol. 2019, 124, 1465-1469. [CrossRef] [PubMed]

34. Al-Bawardy, R.; Rosenfield, K.; Borges, J.; Young, M.N.; Albaghdadi, M.; Rosovsky, R.; Kabrhel, C. Extracorporeal membrane oxygenation in acute massive pulmonary embolism: A case series and review of the literature. Perfusion 2019, 34, 22-28. [CrossRef]

35. Soar, J.; Nolan, J.P.; Bottiger, B.W.; Perkins, G.D.; Lott, C.; Carli, P.; Pellis, T.; Sandroni, C.; Skrifvars, M.B.; Smith, G.B.; et al. European Resuscitation Council Guidelines for Resuscitation 2015: Section 3. Adult advanced life support. Resuscitation 2015, 95, 100-147. [CrossRef] [PubMed]

36. Pasrija, C.; Kronfli, A.; George, P.; Raithel, M.; Boulos, F.; Herr, D.L.; Gammie, J.S.; Pham, S.M.; Griffith, B.P.; Kon, Z.N. Utilization of Veno-Arterial Extracorporeal Membrane Oxygenation for Massive Pulmonary Embolism. Ann. Thorac. Surg. 2018, 105, 498-504. [CrossRef] 